\title{
Zinc and water intake in rats: investigation of adrenergic and opiatergic central mechanisms
}

J.B. Fregoneze ${ }^{1}$, C.P. Luz ${ }^{2}$, L. Castro ${ }^{2}$, P. Oliveira ${ }^{1}$, A.K.S. Lima2, F. Souza2, I. Maldonado², D.F. Macêdo², M.G. Ferreira2, I.P.V. Bandeira2, M.A. Rocha Jr. ${ }^{2}$, F.L.Q. Carvalho ${ }^{2}$ and E. De-Castro-e-Silva ${ }^{2}$
${ }^{1}$ Departamento de Zoologia, Instituto de Biologia, and 2Departamento de Fisiologia, Instituto de Ciências da Saúde, Universidade Federal da Bahia, Salvador, BA, Brasil

\section{Correspondence}

J.B. Fregoneze

Departamento de Zoologia

Instituto de Biologia, UFBA

40170-110 Salvador, BA

Brasil

Fax: +55-71-337-0195

E-mail: josmara@ svn.com.br

Research supported by CNPq (Nos. 300772/86-2 and 301099/92-8) and CADCT.

Received March 4, 1999 Accepted July 15, 1999

\section{Abstract}

We have demonstrated that central administration of zinc in minute amounts induces a significant antidipsogenic action in dehydrated rats as well as in rats under central cholinergic and angiotensinergic stimulation. Here we show that acute third ventricle injections of zinc also block water intake induced by central ß-adrenergic stimulation in Wistar rats (190-250 g). Central inhibition of opioid pathways by naloxone reverses the zinc-induced antidipsogenic effect in dehydrated rats. After $120 \mathrm{~min}$, rats receiving third ventricle injections of isoproterenol (160 nmol/rat) exhibited a significant increase in water intake $(5.78 \pm 0.54 \mathrm{ml} / 100 \mathrm{~g}$ body weight $)$ compared to saline-treated controls $(0.15 \pm 0.07 \mathrm{ml} / 100 \mathrm{~g}$ body weight $)$. Pretreatment with zinc (3.0, 30.0 and $300.0 \mathrm{pmol} / \mathrm{rat}, 45 \mathrm{~min}$ before isoproterenol injection) blocked water intake in a dose-dependent way. At the highest dose employed a complete blockade was demonstrable $(0.54 \pm 0.2 \mathrm{ml} / 100$ $\mathrm{g}$ body weight). After $120 \mathrm{~min}$, control (NaAc-treated) dehydrated rats, as expected, exhibited a high water intake $(7.36 \pm 0.39 \mathrm{ml} / 100 \mathrm{~g}$ body weight). Central administration of zinc blocked this response $(2.5 \pm 0.77 \mathrm{ml} / 100 \mathrm{~g}$ body weight $)$. Naloxone pretreatment $(82.5 \mathrm{nmol} /$ rat, $30 \mathrm{~min}$ before zinc administration) reverted the water intake to the high levels observed in zinc-free dehydrated animals $(7.04 \pm 0.56 \mathrm{ml} /$ $100 \mathrm{~g}$ body weight). These data indicate that zinc is able to block water intake induced by central $ß$-adrenergic stimulation and that zincinduced blockade of water intake in dehydrated rats may be, at least in part, due to stimulation of central opioid peptides.

Zinc, a divalent cation with multiple biochemical and physiological functions, may play important neuromodulatory roles in the central nervous system. After a selective and controlled brain uptake, zinc is found in distinct nerve fibers, widely distributed throughout several regions but with a clear

\author{
Key words \\ - Zinc \\ - Isoproterenol \\ - Opioids \\ - Thirst \\ - Naloxone \\ - Rats
}

telencephalic predominance (1). Specific and non-specific neuronal carriers provide zinc entry into central neurons, in some of which metal ion is stored in synaptic vesicles. Modulation of excitatory and inhibitory amino acid transmission is among the many putative roles ascribed to brain zinc. Indeed, zinc is 
co-released with glutamate and modulates glutamatergic excitation by inhibiting $\mathrm{N}$ methyl-D-aspartate (NMDA) receptors, and prevents gamma-aminobutyric acid (GABA) inhibition by blocking $\mathrm{GABA}_{\mathrm{A}}$ receptor function (2).

We have demonstrated that central injection of minute amounts of zinc into the third ventricle induces a significant antidipsogenic effect in rats under several conditions (3), an action that seems to depend on the functional integrity of voltage-dependent calcium channels (4). We have also shown that serotonin receptor $5-\mathrm{HT}_{1 \mathrm{~A}}$ stimulation may be one of the mechanisms underlying zinc-induced thirst inhibition (5).

The investigation of the function of central zinc is relevant, first, because it should clarify important physiological questions concerning this unique ionic neuromodulator and, second, in view of the possible contribution of brain zinc to the genesis of neurological conditions such as neurotoxicity and convulsive disorders.

In the present study we show that acute third ventricle injection of zinc inhibits water intake induced by central $ß$-adrenergic stimulation and that the antidipsogenic effect of zinc may rely on an opioid-dependent mechanism.

We used adult Wistar male rats weighing 190-250 g kept under controlled light and temperature conditions (lights on from 6:00 to 20:00 h). The animals were cannulated in the third ventricle seven days before the experimental sessions, as described elsewhere (6). Briefly, the animals were anesthetized with sodium pentobarbital $(40 \mathrm{mg} /$ $\mathrm{kg}, i p$ ) and a 28-gauge stainless steel cannula was stereotaxically implanted into the third ventricle (anteroposterior $=0.5 \mathrm{~mm}$ behind the bregma, lateral $=$ just on the midline, and vertical $=8.5 \mathrm{~mm}$ below the skull). The cannulas were provided with a 28 -gauge mandril to avoid obstruction. They were firmly anchored to the skull with two screws embedded in the bone and cemented with dental acrylic. After the experiments, $2 \mu \mathrm{l}$ of 5\% Evans blue was injected into the third ventricle through the cannula in order to determine its position in the brain. Only data from those animals whose cannulas were correctly placed in the third ventricle are reported. Zinc acetate $\left(\mathrm{Zn}(\mathrm{Ac})_{2}\right)$, sodium acetate (NaAc), isoproterenol (ISO) and naloxone (NAL) were obtained from Sigma Chemical Co., St. Louis, MO, USA. All drugs were dissolved in isotonic saline solution. Third ventricle injections were made with a Hamilton microsyringe connected to a Mizzy-Slide-Pak needle through a polyethylene extension. Injections were performed over a period of $60 \mathrm{~s}$ in a volume of $2 \mu 1$. All experiments were conducted between 8:00 and 11:00 a.m., always on naive animals.

To investigate the effect of zinc on ISOinduced water intake, normohydrated animals were treated with third ventricle injection of ISO (160 nmol), after pretreatment (45 min before) with different doses (0.3, $3.0,30.0$ and $300.0 \mathrm{pmol} / \mathrm{rat})$ of $\mathrm{Zn}(\mathrm{Ac})_{2}$ or with NaAc at the dose of $3.0 \mathrm{nmol} / \mathrm{rat}$ (controls). We also investigated the influence of opiates on zinc-induced inhibition of drinking behavior in dehydrated animals. Animals were dehydrated (14 h overnight just before the experimental session) and were pretreated with naloxone (10.3 and 82.5 nmol/rat) or saline (controls) $30 \mathrm{~min}$ before receiving third ventricle injection of $\mathrm{Zn}(\mathrm{Ac})_{2}$ at the dose of $3.0 \mathrm{pmol} / \mathrm{rat}$. In all cases cumulative water intake was recorded throughout the 120 min following the second injection.

Data were analyzed statistically by repeated measures analysis of variance (ANOVA) followed by the StudentNewman-Keuls test using the GBSTAT computer software (SigmaStat for Windows, Jandel Scientific, San Rafael, CA, USA). Differences were considered significant when $\mathrm{P}<0.05$. The cumulative water intake is presented as $\mathrm{ml} / 100 \mathrm{~g}$ body weight (mean \pm SEM). 
Figure 1 summarizes the results of the first experimental set, showing the effect of zinc pretreatment on ISO-induced water intake. Animals treated with ISO at the dose of $160 \mathrm{nmol}$ and pretreated with saline (saline + ISO) exhibited a significant increase in water intake as compared to control animals (saline + saline). Animals treated with ISO at the same dose but pretreated with $\mathrm{Zn}(\mathrm{Ac})_{2}$ (Zn + ISO) displayed a dose-dependent reduction in ISO-induced water intake. At the lowest dose employed $(0.3 \mathrm{pmol} / \mathrm{rat}) \mathrm{Zn}(\mathrm{Ac})_{2}$ did not evoke a significant decrease in the drinking behavior induced by third ventricle injection of ISO. Administration of the subsequent doses of $\mathrm{Zn}(\mathrm{Ac})_{2}$ (3.0, 30.0, and $300.0 \mathrm{pmol} / \mathrm{rat}$ ) led to a progressive decline in ISO-induced water intake. At all effective doses the inhibitory effect of zinc administration was evident after $45 \mathrm{~min}$ of water intake recording, persisting until the end of the experiment.

In the second experimental set we analyzed the effects of third ventricle administration of naloxone at two different doses (10.3 and $82.5 \mathrm{nmol} / \mathrm{rat}$ ) on the antidipsogenic effect of zinc in dehydrated animals. Figure 2 shows that, as expected, dehydrated control animals (saline $+\mathrm{NaAc}$ ) exhibited a high water intake. Those receiving zinc but pretreated with saline (saline $+\mathrm{Zn}$ ) displayed a significant reduction in water intake as compared to the high values presented by control animals. Naloxone pretreatment reversed the blockade of drinking behavior induced by zinc. Indeed, the water intake of animals pretreated with naloxone at the highest dose employed $(82.5 \mathrm{nmol} / \mathrm{rat})$ and receiving $\mathrm{Zn}(\mathrm{Ac})_{2}(\mathrm{NAL}+\mathrm{Zn})$ was significantly higher than that of animals receiving $\mathrm{Zn}(\mathrm{Ac})_{2}$ but pretreated with saline (saline + $\mathrm{Zn}$ ). This difference was demonstrable after 15 min of water intake recording and lasted until the end of the experiment. At the lowest dose employed $(10.3 \mathrm{nmol} / \mathrm{rat})$, naloxone administration reversed the effect of zinc only at 15 and $30 \mathrm{~min}$. Third ventricle injec-

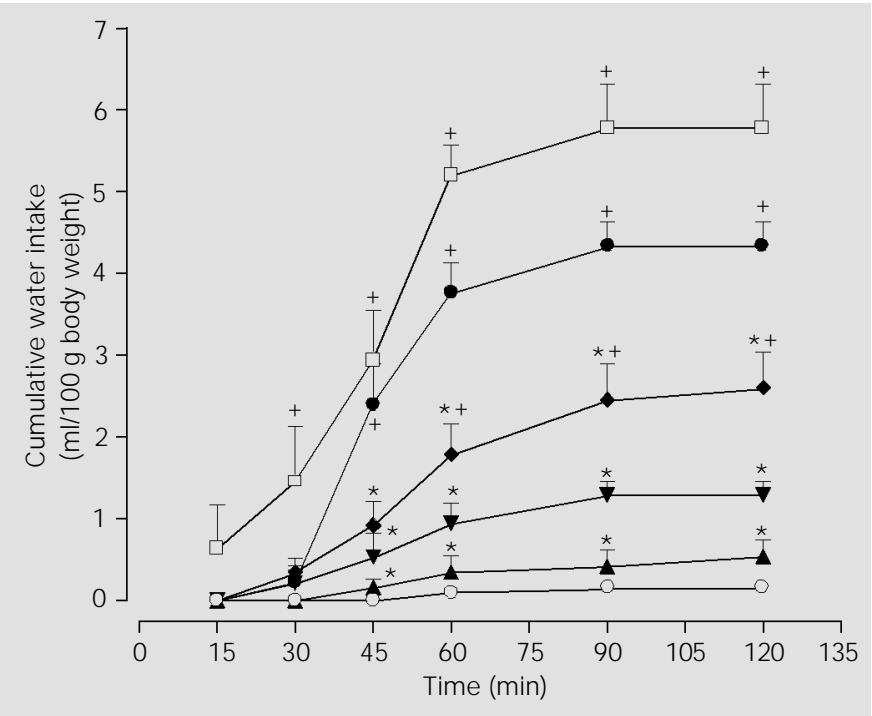

Figure 1 - Effect of zinc pretreatment on the dipsogenic effect of third ventricle isoproterenol (ISO) injection. Cumulative water intake $(\mathrm{ml} / 100 \mathrm{~g}$ body weight) is reported as mean \pm SEM in: (open circles) normohydrated control rats (NaAc + saline); (squares) animals treated with ISO (160 nmol/ rat) pretreated with saline (saline + ISO); animals pretreated with (closed circles) 0.3, (lozenges) 3.0, (inverted triangles) 30.0 and (triangles) 300.0 $\mathrm{pmol} / \mathrm{rat}$ of $\mathrm{Zn}(\mathrm{Ac})_{2}$ and treated with $160 \mathrm{nmol} / \mathrm{rat}$ of ISO. $* \mathrm{P}<0.05 \mathrm{compared}$ to the saline + ISO group; $+\mathrm{P}<0.05$ compared to the $\mathrm{NaAC}+$ saline group (ANOVA followed by the Student-Newman-Keuls test).

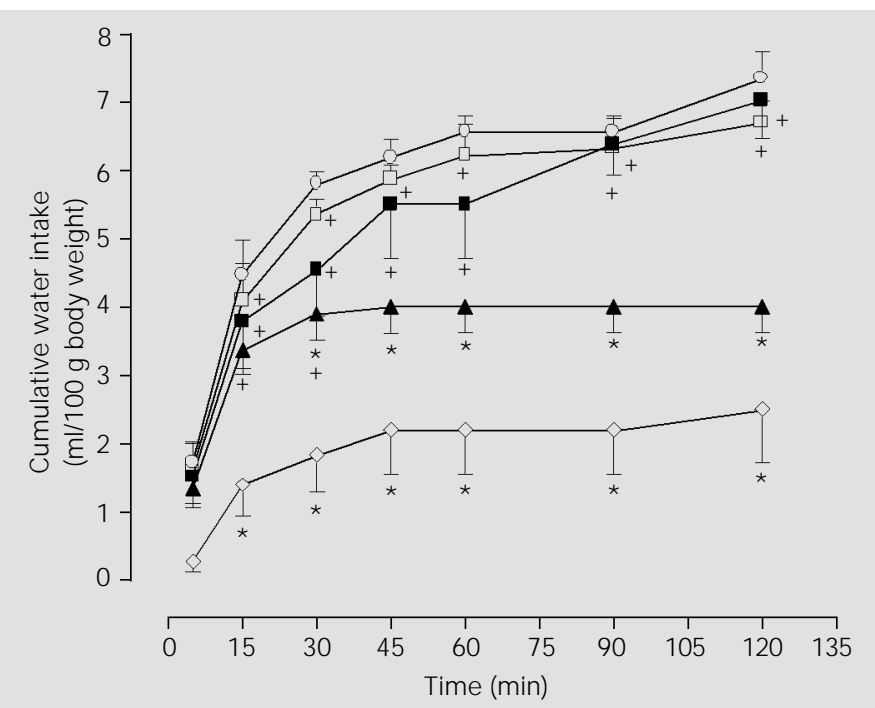

Figure 2 - Effect of naloxone pretreatment on zinc-induced inhibition of water intake in dehydrated rats. Cumulative water intake $(\mathrm{ml} / 100 \mathrm{~g}$ body weight) is presented as mean \pm SEM in: (open circles) animals pretreated with saline and treated with $\mathrm{NaAc}$ (saline + NaAc); (lozenges) animals pretreated with saline and treated with $\mathrm{Zn}(\mathrm{Ac})_{2}$ at the dose of $3.0 \mathrm{nmol} / \mathrm{rat}$ (saline $+\mathrm{Zn}$ ); (triangles) animals pretreated with naloxone (NAL) $(10.3 \mathrm{nmol} /$ rat) and treated with the same dose of zinc (NAL $+Z n$ ); (filled squares) animals pretreated with naloxone $(82.5 \mathrm{nmol} / \mathrm{rat})$ and treated with the same dose of zinc (NAL $+\mathrm{Zn}$ ); (open squares) animals pretreated with naloxone $(82.5 \mathrm{nmol} / \mathrm{rat})$ and treated with NaAc (NAL $+\mathrm{NaAc}) . * \mathrm{P}<0.05$ compared to the saline + NaAc group; ${ }^{+} \mathrm{P}<0.05$ compared to the saline $+\mathrm{Zn}(\mathrm{Ac})_{2}$ group (ANOVA followed by the Student-Newman-Keuls test). 
tion of naloxone alone had no effect on water intake.

The present results extend previous data about central zinc and thirst regulation. We have already demonstrated that zinc inhibits water intake in dehydrated rats as well as in rats whose drinking is evoked by central cholinergic and angiotensinergic stimulation (3). The present data provide information about two unexplored aspects of zinc-induced thirst inhibition. First, we demonstrate that acute third ventricle injections of zinc block the dipsogenic action of central $\beta$ adrenergic stimulation. Second, we confirm the antidipsogenic effect of zinc in dehydrated rats, and show that in this group of animals zinc-induced thirst inhibition may be dependent, at least in part, on stimulation of central opioid pathways, since naloxone, a non-specific opioid receptor antagonist, partially reversed the antidipsogenic effect of zinc.

Zinc may represent an intriguing neuromodulator in the central nervous system. It is actively transported into the brain by specific carriers (7) and is stored in synaptic vesicles of different neuronal pathways. It is co-localized and co-released with glutamatergic nerve fibers and mediates glutamate activity through a voltage-independent block of NMDA receptors (8). It also inhibits GABAergic transmission (9). Besides altering brain function by a modulatory action on amino acid transmission, zinc may induce myriad effects through a modification of ligand/ receptor affinities and interactions due to its ability to alter the quaternary structure of several proteins. Modification of neurotransmitter or neuromodulator release may represent another mode by which zinc alters brain function (1).

In the present study, acute intracerebroventricular injections of zinc induced a dosedependent decrease in isoproterenol-induced water intake. Thirst regulation by the brain is the result of a complex interactive circuitry involving different regions and neurotrans- mitters related to many aspects of the homeostatic control of body fluid and electrolytes. Brain angiotensinergic and cholinergic components stimulate water intake, whereas opioids and serotonin have the opposite effect (10). Central ß-adrenergic pathways correspond to a further thirst-stimulatory component and, indeed, part of the dipsogenic effect of brain angiotensin II may be consequent to norepinephrine release (11). As mentioned earlier, in a previous paper we showed that zinc is able to induce a blockade of water intake induced by cholinergic and angiotensinergic stimulation (3). It is now clear that water intake generated by central $\beta$-adrenergic stimulation is also blocked by zinc. This means that the metal disrupts the functional integrity of some mechanism that is triggered by all the most important central pathways involved in thirst generation.

However, it is possible that zinc inhibits water intake by stimulating central pathways involved in thirst inhibition. For this reason, we determined if zinc-induced antidipsogenesis relies on an opioid-dependent mechanism.

It is generally accepted that opioid circuitries in the central nervous system exert an inhibitory effect on water intake. Indeed, several naturally occurring opioids inhibit angiotensin II-induced drinking (12). In the present paper, naloxone, a non-selective opioid receptor antagonist, was able to reverse the antidipsogenic effect of zinc on water intake in dehydrated rats.

The relationship between zinc and opioid peptides in the brain is an underexplored area. However, a few reports indicate that zinc decreases the affinity of some endogenous peptides for their receptors $(13,14)$. If this is true, the reversal of zinc-induced thirst inhibition by naloxone may mean that zinc increases opioid release to a sufficient extent to express its action even in the presence of a decrease in opioid receptor affinity. Evidently, with the protocol used here, it was impossible to test this hypothesis. 
For the sake of clarity, we should state that, even though most reports indicate that central opioid peptides mainly inhibit drinking behavior, others suggest an opioid-induced increase in drinking (15). However, the present results clearly favor the hypothesis that central opioid peptides inhibit drinking. Indeed, naloxone reversal of zinc-induced inhibition of drinking may only mean that central opioids exert a negative effect on thirst.

Dehydrated animals receiving third ventricle injections of naloxone alone exhibited a high water intake similar to that displayed by the control group. This is additional evidence in favor of the central opioid inhibitory effect on drinking. In dehydrated animals, whose willingness to drink must be increased, the thirst-inhibiting inputs must be suppressed. Thus, since the endogenous opioid input along pathways controlling thirst in dehydrated rats is very low, injection of naloxone alone is devoid of any effect.

Zinc concentration in the brain is normally within the 10-100 $\mu \mathrm{mol}$ range (1). This is far above the doses used here. Thus, it is reasonable to assume that the present results may denote the physiological relevance of zinc in the phenomena observed.

It is noteworthy that the amount of zinc necessary to block ISO-induced water intake is considerably lower than that needed to block drinking in dehydrated rats. The dif- ference in zinc potency to block the two phenomena is astonishingly large. Indeed, ISO-induced drinking is blocked when zinc is injected at doses in the picomolar range whereas nanomolar concentrations are required to block water intake in dehydrated rats, as shown in the present study. Angiotensin- and carbachol-induced drinking is also inhibited by nanomolar concentrations of zinc, as previously shown by our group (3). This suggests that ISO-induced drinking relies on a distinct mechanism much more likely to be blocked by zinc than those triggered by the other dipsogenic situations.

In conclusion, the present results indicate that acute third ventricle injection of zinc inhibits water intake induced by central $\beta$-adrenergic stimulation by isoproterenol, and that naloxone reverses zinc-induced antidipsogenesis in dehydrated rats, indicating that the inhibitory effect of zinc on water intake may be, at least in part, opioid-dependent. Additionally, the present data support the hypothesis that central opioid peptides exert an inhibitory effect on drinking behavior.

\section{Acknowledgments}

We thank Mr. Vanilson Souza and Mr. José de Souza for skillful technical assistance.

\section{References}

1. Vallee BL \& Falchuk KH (1993). The biochemical basis of zinc physiology. Physiological Reviews, 73: 79-118.

2. Huang EP (1997). Metal ions and synaptic transmission: Think zinc. Proceedings of the National Academy of Sciences, USA, 94: 13386-13387.

3. Fregoneze J B, Souza C, Cunha M, Ferreira H, De-Oliveira I, Barros L, Malbouisson M \& De-Castro-e-Silva E (1994). Acute effects of intracerebroventricular administration of zinc on the drinking behavior of rats induced by dehydration or central cho- linergic and angiotensinergic stimulation. Brazilian J ournal of Medical and Biological Research, 27: 2623-2633.

4. DeCastro-e-Silva E, Marinho CA, Soares T, Castro L, Sarmento C, Cunha M, Gonzalez V, Oliveira P, Nascimento T, Luz CP, Santana J r P, DeOliveira IR \& Fregoneze J B (1996). Calcium channel blockers inhibit the antidipsogenic effect of central injections of zinc in rats. Brazilian J ournal of Medical and Biological Research, 29: 1651-1655.

5. Fregoneze J B, Ferreira H, Soares T, Luz
CP, Bulcão C, Nascimento T, Marinho CA, Sarmento C, De-Oliveira IR, Cunha M \& De-Castro-e-Silva E (1995). SDZ 216-525, a selective $5-\mathrm{HTl}_{\mathrm{A}}$ receptor antagonist, reverts zinc-induced inhibition of water intake in dehydrated rats. Brazilian J ournal of Medical and Biological Research, 28: 711-714.

6. Antunes-Rodrigues J \& McCann SM (1970). Water, sodium and food intake induced by injections of cholinergic and adrenergic drugs into the third ventricle of rat brain. Proceedings of the Society for 
Experimental Biology and Medicine, 133: 1464-1470.

7. Palmiter RD, Cole TB, Quaife CJ \& Findley SD (1996). Zn-T3, a putative transporter of zinc into synaptic vehicles. Proceedings of the National Academy of Sciences, USA, 93: 14934-14939.

8. Chen N, Moshaver A \& Raymond LA (1997). Differential sensitivity of recombinant N-methyl-D-aspartate receptor subtypes to zinc inhibition. Molecular Pharmacology, 51: 1015-1023.

9. Berger T, Schwarz C, Kraushaar U \& Monyer H (1998). Dentate gyrus basket cell GABA $A$ receptors are blocked by $\mathrm{Zn}^{2+}$ via changes of their desensitization kinet- ics: An in situ patch-clamp and single-cell PCR study. J ournal of Neuroscience, 18 : 2437-2448.

10. J ohnson AK \& Thunhorst RL (1997). The neuroendocrinology of thirst and salt appetite: Visceral sensory signals and mechanisms of central integration. Frontiers in Neuroendocrinology, 18: 292-353.

11. Fitzsimons J T (1998). Angiotensin, thirst, and sodium appetite. Physiological Reviews, 78: 583-686.

12. Summy-Long J Y, Keil LC, Deen $K \&$ Severs WB (1981). Opiate regulation of angiotensin-induced drinking and vasopressin release. J oumal of Pharmacology and Experimental Therapeutics, 217: 630-637.
13. Stengaard-Pedersen K (1982). Inhibition of enkephalin binding to opiate receptors by zinc ions: possible physiological importance in the brain. Acta Pharmacologica et Toxicologica, 50: 213-220.

14. Stengaard-Pedersen $K$, Fredens $K \&$ Larsson LI (1981). Inhibition of opiate receptor binding by zinc ions: possible physiological importance in the hippocampus. Peptides, 2(Suppl 1): 27-35.

15. Brown DR \& Holtzman SG (1981). Suppression of drinking by naloxone in the rat: a further characterization. European J ournal of Pharmacology, 69: 331-340. 